\title{
Nonlinear relationship between serum uric acid and body mass index: a cross-sectional study of a general population in coastal China
}

\author{
Hui Zhou ${ }^{2}$, Zhen Liư ${ }^{3}$, Zhong Chao' ${ }^{1}$ Yeqing Chao², Lidan Ma', Xiaoyu Cheng ${ }^{1}$, Yangang Wang ${ }^{1}$, Changgui Li $^{1}$ \\ and Ying Chen ${ }^{1 *}$
}

\begin{abstract}
Background: Conflicting evidence exists on the relationship between body mass index (BMI) and serum uric acid (SUA). Therefore, we aimed to evaluate the SUA-BMI relationship in a large-scale epidemiological survey in coastal China.

Methods: This survey was conducted among the general population in the coastal region of China from September 2014 to January 2015. SUA Levels were measured by the automatic Sysmex Chemix-180 biochemical analyzer.

Results: A total of 6098 men (BMI: $\left.24.58 \pm 3.74 \mathrm{~kg} / \mathrm{m}^{2}\right)$ and 7941 women $\left(24.56 \pm 3.64 \mathrm{~kg} / \mathrm{m}^{2}\right)$ were included in this study. A stronger positive BMI-SUA association was found for men than women (all $P$-values $<0.05$ ). The piecewise linear spline models indicated a U-shaped relationship of SUA-BMI association for both men and women; and the lowest turning points were at $19.12 \mathrm{~kg} / \mathrm{m}^{2}$ for men and $21.3 \mathrm{~kg} / \mathrm{m}^{2}$ for women. When BMls were lower than the nadir point, each $1 \mathrm{~kg} / \mathrm{m}^{2}$ increase in BMl related to a 7.74 -fold $(95 \% \mathrm{Cl}-14.73,-0.75)$ reduction for men and 2.70-fold reduction $(-4.47,-0.94)$ for women in SUA levels. Once the BMI was higher than the nadir point, each $1 \mathrm{~kg} / \mathrm{m}^{2}$ increase in BMI was related to a 5.10 -fold $(4.44,5.77)$ increment for men and 3.93-fold increment $(3.42,4.43)$ for women in SUA levels. The regression coefficient differences between the two stages were $12.84(5.66,20.03)$ for men and $6.63(4.65,8.61)$ for women.
\end{abstract}

Conclusions: A U-shaped relationship between BMI and SUA was found for both men and women; the association was stronger for men than women.

Keywords: Uric acid, Serum, Body mass index, Cross-sectional studies, Epidemiology, China

\section{Background}

As the end product of the metabolic breakdown of purine nucleotides [1], an increasing amount of research has indicated that the role of uric acid (UA) in metabolic syndrome has changed from innocent bystander to central player [2] and UA plays a key role in the development of hypertension [3, 4], hyperglycemia [5], hyperlipidemia [6], and also obesity [7]. Obesity, a multiple organ-system disease with underlying metabolic abnormalities, is a

\footnotetext{
*Correspondence: qdchenying@126.com

${ }^{1}$ Department of Endocrinology and Metabolism, The Affiliated Hospital of Qingdao University, 16 Jiangsu Road, Qingdao, Shandong 266003,

China

Full list of author information is available at the end of the article
}

public health crisis and results in a huge economic burden $[8,9]$. A series of cross-sectional studies suggested a positive association between serum uric acid (SUA) and body mass index (BMI) [10-13], which was demonstrated in a population-based longitudinal study [7]. However, limited data is available in the Chinese population.

In addition, several laboratory studies have suggested discrimination in the SUA-BMI association among different BMI levels [3, 14-16]. Our previous study also found that SUA and blood pressure (BP) might have a nonlinear, instead a simple linear, relationship [3]. Therefore, in this study, we used data from a large cross-sectional study in China to better understand the relationship between SUA and BMI, and additionally explore whether other 
metabolic factors may affect the relationship between SUA and BMI.

\section{Methods}

\section{Study population}

This is a population-based cross-sectional study among people in the coastal region of China, from August 2004 to December 2014. Participants were excluded if one of the following criteria were met: (I) medication use to lower weight, serum lipids, uric acid, blood sugar or blood pressure; (II) history of liver, severe renal, or heart diseases. A total of 14,039 participants (6098 males and 7941 females) met the criteria for enrollment in this study. The study protocol was approved by the ethics committee of the Affiliated Hospital of Qingdao University and informed consent was obtained from each participant.

\section{Data collection and measures}

The participants' demographic and lifestyle information were collected using a standard questionnaire by in-person interview, including current smoking status (smoker, never, past), alcohol consumption (never, moderate, heavy, past), and occupation type (light, moderate, heavy physical). BMI was calculated as weight $(\mathrm{kg})$ per height squared $\left(\mathrm{m}^{2}\right)$ and categorized as: under-weight $\left(\mathrm{BMI}<18.5 \mathrm{~kg} / \mathrm{m}^{2}\right)$, normal weight $\left(18.5 \mathrm{~kg} / \mathrm{m}^{2} \leq \mathrm{BMI}<24.9 \mathrm{~kg} / \mathrm{m}^{2}\right)$, overweight $(25 \mathrm{~kg} /$ $\left.\mathrm{m}^{2} \leq \mathrm{BMI}<29.9 \mathrm{~kg} / \mathrm{m}^{2}\right)$, and obesity $\left(\mathrm{BMI} \geq 30 \mathrm{~kg} / \mathrm{m}^{2}\right)$. For alcohol consumption in past 6 months, different from that used in the US and EU, heavy drinking was defined as equal as or greater than one time per week; and moderate drinking was defined as drinking at holiday and festival days, averagely one time per month. For occupation types, the "light physical" jobs referred to those with sedentary/desk job, such as official staffs, teachers and light physical houseworkers. Moderate physical work included students, gym teachers, and light physical farmworkers. And heavy physical works referred to the porter (workers who employed to help carry, ship or move luggage or other loads), construction workers, athletes, and so on. BP was measured with a standard mercury sphygmomanometer, and subjects were required to rest for at least 15 min before BP measurement. All measurements of height, weight, and BP were carried out by the same group of seven professional physicians.

Elbow venous blood $(5 \mathrm{~mL}$ ) was extracted from all participants after fasting for at least $12 \mathrm{~h}$. The fasting blood glucose (FBG), triglyceride (TG), total cholesterol (TC), creatinine, high/low-density lipoprotein cholesterol (H/LDL), and SUA levels of all blood specimens were examined by automatic Sysmex Chemix-180 biochemical analyzer (Nanchang Micare Medical Equipment Co.,
LTD, Jiangxi, China). Estimated glomerular filtration rate (eGFR) was calculated by the following formula: $\mathrm{eGFR}=175 \times(\text { creatinine } / 88.4)^{-1.234} \times$ age $^{-0.179} \times(0.79$ for females). Hyperuricemia was diagnosed if SUA levels were higher than $420 \mu \mathrm{mol} / \mathrm{L}$ for men and postmenopausal women, and higher than $357 \mu \mathrm{mol} / \mathrm{L}$ for premenopausal women.

\section{Statistical analyses}

Previous studies suggested large differences in BMI and SUA among men and women; therefore, all analyses were separately applied to men and women. We calculated mean \pm standard deviation (SD) and median (interquartile range) for frequency of participant characteristics, t-tests for normal distributions, Kruskal-Wallis tests for non-normal distributions, and Chi square tests were used to compare characteristic differences among men and women. We evaluated the possible linear and nonlinear relationships between SUA and BMI by multivariate linear regression models and two-piece piecewise regression models adjusted for age, current alcohol consumption status, current smoking status, occupation type, systolic blood pressure (SBP), diastolic blood pressure (DBP), FBS (log transformed), eGFR, low density lipoprotein (LDL), and TC, among men and women. We further conducted stratified and interaction analyses to explore the potential modifier and interaction effects on the SUA-BMI association. Before these, covariate screening was also performed among all variables included in Table 1 using univariate analysis. $93.7 \%$ of the participants enrolled in our study had complete data, and only those participants with complete data were included in the analysis.

All statistical analyses were performed using Empower Stats software (X\&Y Solutions, Inc., Boston, USA). $P<0.05$ was considered statistically significant.

\section{Results}

\section{Characteristics of the participants}

A total of 14,039 participants aged $48.24 \pm 13.94$ years, of which $56.6 \%$ were women, met the criteria for enrollment and were included in the analyses. The overall mean level of SUA was $303.09( \pm 87.50) \mu \mathrm{mol} / \mathrm{L}$, which was significantly higher among men $(349.62 \pm 85.30 \mu \mathrm{mol} / \mathrm{L})$ than women $(267.37 \pm 70.79 \mu \mathrm{mol} / \mathrm{L})$. Hyperuricemia was diagnosed in $10 \%$ of participants, and hyperuricemia prevalence was significantly lower among women (4.04\%) than men (17.96\%) (Table 1).

After stratification by BMI, SUA levels increased from $273.62 \pm 72.84 \mu \mathrm{mol} / \mathrm{L}$ for under-weight participants to $341.60 \pm 93.59 \mu \mathrm{mol} / \mathrm{L}$ for obese participants (Table 2). Also, obese participants tended to be older, with less 
Table 1 Characteristics of 7941 women and 6098 men included in this study

\begin{tabular}{|c|c|c|c|c|}
\hline Characteristics & Men & Women & Total & P-value \\
\hline$n$ & 6098 & 7941 & 14,039 & \\
\hline Hyperuricemia & $17.96 \%$ & $4.04 \%$ & $10.18 \%$ & $<0.001$ \\
\hline Age (years) & $47.70 \pm 14.28$ & $48.65 \pm 13.65$ & $48.24 \pm 13.94$ & $<0.001$ \\
\hline Body mass index $\left(\mathrm{kg} / \mathrm{m}^{2}\right)$ & $24.54 \pm 3.51$ & $24.58 \pm 3.74$ & $24.56 \pm 3.64$ & 0.535 \\
\hline Occupation types & & & & $<0.001$ \\
\hline Light physical & $3266(53.56)$ & $5606(70.60)$ & $8872(63.20)$ & \\
\hline Moderate physical & $2123(34.81)$ & $1901(23.94)$ & $4024(28.66)$ & \\
\hline Heavy physical & 709 (11.63) & $434(5.47)$ & $1143(8.14)$ & \\
\hline Serum uric acid ( $\mu \mathrm{mol} / \mathrm{L})$ & $349.62 \pm 85.30$ & $267.37 \pm 70.79$ & $303.09 \pm 87.50$ & $<0.001$ \\
\hline Smoking status in last 6 months (\%) & & & & $<0.001$ \\
\hline Smoking & $2804(45.98)$ & $7769(97.83)$ & $10,573(75.31)$ & \\
\hline Never & $2972(48.74)$ & $152(1.91)$ & $3124(22.25)$ & \\
\hline Past & $322(5.28)$ & $20(0.25)$ & $342(2.44)$ & \\
\hline Alcohol drinking status in last 6 months (\%) & & & & $<0.001$ \\
\hline Never & $2659(43.60)$ & $7698(96.94)$ & $10,357(73.77)$ & \\
\hline Moderate & $2204(36.14)$ & $180(2.27)$ & $2384(16.98)$ & \\
\hline Heavy & $1161(19.04)$ & $62(0.78)$ & $1223(8.71)$ & \\
\hline Quit & $74(1.21)$ & $1(0.01)$ & $75(0.53)$ & \\
\hline Systolic blood pressure (mmHg) & $131.76 \pm 19.38$ & $129.73 \pm 22.13$ & $130.61 \pm 21.01$ & $<0.001$ \\
\hline Diastolic blood pressure (mmHg) & $85.68 \pm 12.07$ & $82.49 \pm 11.82$ & $83.87 \pm 12.03$ & $<0.001$ \\
\hline Fasting blood glucose (mmol/L) & $5.10(4.42-5.70)$ & $5.08(4.50-5.68)$ & $5.09(4.48-5.70)$ & 0.362 \\
\hline Triglyceride (mmol/L) & $1.20(0.82-1.90)$ & $1.10(0.74-1.66)$ & $1.14(0.77-1.76)$ & $<0.001$ \\
\hline High-density lipoprotein cholesterol (mmol/L) & $1.31 \pm 0.42$ & $1.40 \pm 0.38$ & $1.36 \pm 0.40$ & $<0.001$ \\
\hline Low-density lipoprotein cholesterol (mmol/L) & $2.76 \pm 0.82$ & $2.74 \pm 0.84$ & $2.75 \pm 0.83$ & 0.330 \\
\hline Total cholesterol (mmol/L) & $4.86 \pm 1.04$ & $4.88 \pm 1.09$ & $4.87 \pm 1.07$ & 0.277 \\
\hline Creatinine $(\mu \mathrm{mol} / \mathrm{L})$ & $82.98 \pm 21.77$ & $70.11 \pm 21.07$ & $75.70 \pm 22.31$ & $<0.001$ \\
\hline Estimated glomerular filtration rate $\left(\mathrm{mL} / \mathrm{min} / 1.73 \mathrm{~m}^{2}\right)$ & $90.54(76.98-126.17)$ & $85.45(73.57-127.39)$ & $89.15(75.28-136.30)$ & $<0.001$ \\
\hline
\end{tabular}

healthy lifestyles, and higher SBP, DBP, fasting glucose and cholesterol levels (all $P$-values $<0.05$ ).

\section{Linear relationship between SUA and BMI}

The linear regression models suggested a significant association between SUA and BMI in both men and women, after adjustment for age, current smoking status, current alcohol consumption status, occupation types, SBP, DBP, FBS, LDL, TG, TC, and eGFR (all $P$-values $<0.05)$. In women, SUA levels were significantly increased by $3.03 \mu \mathrm{mol} / \mathrm{L}(95 \%$ CI $2.60,3.46 \mu \mathrm{mol} / \mathrm{L}$ ) for each SD $\left(3.74 \mathrm{~kg} / \mathrm{m}^{2}\right)$ increase in BMI. Similar results were observed for men where SUA levels were elevated by $4.71 \mu \mathrm{mol} / \mathrm{L}(95 \% \mathrm{CI} 4.08,5.35 \mu \mathrm{mol} / \mathrm{L})$ for each $\mathrm{SD}$ $\left(3.51 \mathrm{~kg} / \mathrm{m}^{2}\right)$ increase in BMI (Table 3).

\section{Nonlinear relationship between SUA and BMI}

A U-shaped relationship between SUA and BMI was observed for both women and men by piecewise regression model; and the estimated nadir point was $19.1 \mathrm{~kg} / \mathrm{m}^{2}$ for men and $21.3 \mathrm{~kg} / \mathrm{m}^{2}$ for women (Fig. 1 and Table 3).
For men, once the BMI was lower than $19.1 \mathrm{~kg} / \mathrm{m}^{2}$, a significantly positive association between BMI and SUA was found, and the regression coefficient was -7.74 (95\% CI $-14.7,-0.75$; $P=0.03$ ) per SD increase in BMI; while a negative BMI-SUA association was detected if the BMI was higher than $19.1 \mathrm{~kg} / \mathrm{m}^{2}$, and the regression coefficient was 5.10 (95\% CI 4.44, 5.77; $P<0.0001)$ per SD increase in BMI. In women, SUA levels were negatively associated with BMI if the BMI was lower than $21.3 \mathrm{~kg} /$ $\mathrm{m}^{2}$, and the regression coefficient was -2.70 (95\% CI $-4.47,-0.94 ; P=0.003)$ per SD increase in BMI; then when the BMI was higher than $21.3 \mathrm{~km} / \mathrm{m}^{2}$, the SUA levels positively increased with BMI elevation, and the estimated regression coefficient was 3.93 (95\% CI 3.42, 4.43; $P<0.0001)$ per SD increase in BMI.

The calculated differences in regression coefficients higher and lower than the nadir point were 12.8 (95\% CI 5.66, 20.0; $P=0.0005)$ for men and 6.63 (95\% CI 4.65, 8.61; $P<0.0001)$ for women, after adjustment for age, current smoking and alcohol consumption status, SBP, DBP, TC, TG, FBS, and eGFR. 
Table 2 Characteristics of 7941 women and 6098 men among 4 BMI categories in this study

\begin{tabular}{|c|c|c|c|c|c|}
\hline Characteristics & Under-weight & Normal weight & Overweight & Obesity & P-value \\
\hline $\mathrm{n}$ & 470 & 7548 & 4983 & 1038 & \\
\hline Hyperuricemia & $4.81 \%$ & $7.19 \%$ & $13.46 \%$ & $17.68 \%$ & $<0.001$ \\
\hline Age (years) & $42.49 \pm 18.60$ & $46.64 \pm 14.28$ & $50.42 \pm 12.51$ & $51.98 \pm 12.87$ & $<0.001$ \\
\hline Body mass index $\left(\mathrm{kg} / \mathrm{m}^{2}\right)$ & $17.59 \pm 0.75$ & $22.33 \pm 1.73$ & $27.06 \pm 1.36$ & $32.01 \pm 2.21$ & $<0.001$ \\
\hline Occupation types, \% & & & & & $<0.001$ \\
\hline Light physical & $290(61.70)$ & $4555(60.35)$ & $3294(66.10)$ & $733(70.62)$ & \\
\hline Moderate physical & $147(31.28)$ & $2322(30.76)$ & $1311(26.31)$ & $244(23.51)$ & \\
\hline Heavy physical & $33(7.02)$ & $671(8.89)$ & $378(7.59)$ & $61(5.88)$ & \\
\hline Serum uric acid $(\mu \mathrm{mol} / \mathrm{L})$ & $273.62 \pm 72.84$ & $287.58 \pm 82.84$ & $321.35 \pm 88.14$ & $341.60 \pm 93.59$ & $<0.001$ \\
\hline Smoking status in last 6 months (\%) & & & & & $<0.001$ \\
\hline Smoking & $354(75.32)$ & $5575(73.86)$ & $3816(76.58)$ & $828(79.77)$ & \\
\hline Never & $110(23.40)$ & $1792(23.74)$ & $1031(20.69)$ & $191(18.40)$ & \\
\hline Past & $6(1.28)$ & $181(2.40)$ & $136(2.73)$ & $19(1.83)$ & \\
\hline Alcohol drinking status in last 6 months (\%) & & & & & $<0.001$ \\
\hline Never & $373(79.36)$ & $5589(74.05)$ & $3588(72.00)$ & $807(77.75)$ & \\
\hline Moderate & $56(11.91)$ & $1259(16.68)$ & $911(18.28)$ & $158(15.22)$ & \\
\hline Heavy & 38 (8.09) & $657(8.70)$ & $457(9.17)$ & $71(6.84)$ & \\
\hline Quit & $3(0.64)$ & $43(0.57)$ & $27(0.54)$ & $2(0.19)$ & \\
\hline Systolic blood pressure (mmHg) & $118.08 \pm 17.73$ & $126.39 \pm 19.85$ & $135.75 \pm 20.41$ & $142.34 \pm 22.28$ & $<0.001$ \\
\hline Diastolic blood pressure $(\mathrm{mmHg})$ & $76.57 \pm 10.21$ & $81.39 \pm 11.15$ & $86.86 \pm 11.90$ & $90.94 \pm 12.85$ & $<0.001$ \\
\hline Fasting blood glucose (mmol/L) & $4.70(4.10-5.20)$ & $4.92(4.40-5.50)$ & $5.20(4.60-5.88)$ & $5.60(4.90-6.31)$ & $<0.001$ \\
\hline Triglyceride (mmol/L) & $0.78(0.59-1.07)$ & $0.97(0.68-1.44)$ & $1.41(0.96-2.14)$ & $1.70(1.18-2.57)$ & $<0.001$ \\
\hline High-density lipoprotein cholesterol (mmol/L) & $1.47 \pm 0.35$ & $1.41 \pm 0.41$ & $1.30 \pm 0.38$ & $1.27 \pm 0.38$ & $<0.001$ \\
\hline Low-density lipoprotein cholesterol (mmol/L) & $2.39 \pm 0.73$ & $2.65 \pm 0.81$ & $2.89 \pm 0.83$ & $2.95 \pm 0.80$ & $<0.001$ \\
\hline Total cholesterol (mmol/L) & $4.42 \pm 0.96$ & $4.73 \pm 1.06$ & $5.04 \pm 1.05$ & $5.21 \pm 1.03$ & $<0.001$ \\
\hline Creatinine $(\mu \mathrm{mol} / \mathrm{L})$ & $71.03 \pm 21.83$ & $74.47 \pm 23.02$ & $77.37 \pm 21.26$ & $78.73 \pm 21.23$ & $<0.001$ \\
\hline Estimated glomerular filtration rate (\%) & $99.92(80.05-158.5)$ & $91.35(76.59-142.9)$ & $86.36(73.56-126.8)$ & $83.69(72.03-113.2)$ & $<0.001$ \\
\hline
\end{tabular}

Table 3 Multivariable linear and non-linear relationship between sUA and BMI stratified by gender, $\beta$ (95\% CI) of BMI (kg/ $\mathbf{m}^{2}$ )

\begin{tabular}{|c|c|c|c|c|c|c|}
\hline Models & Men & P-value & Women & P-value & Total & P-value \\
\hline \multicolumn{7}{|c|}{ Linear regression model, Per SD increase in BMI } \\
\hline Crude model & $6.11(5.56,6.66)$ & $<0.0001$ & $5.03(4.66,5.40)$ & $<0.0001$ & $5.47(5.15,5.78)$ & $<0.0001$ \\
\hline Model I & $6.16(5.60,6.71)$ & $<0.0001$ & $4.09(3.71,4.48)$ & $<0.0001$ & $5.29(4.97,5.61)$ & $<0.0001$ \\
\hline Model II & $4.71(4.08,5.35)$ & $<0.0001$ & $3.03(2.60,3.46)$ & $<0.0001$ & $3.80(3.44,4.17)$ & $<0.0001$ \\
\hline \multicolumn{7}{|c|}{ Non-linear model, regression coefficients $(\beta)$} \\
\hline Break point of $\mathrm{BMI}, \mathrm{kg} / \mathrm{m}^{2}(\mathrm{~K})$ & 19.1 & & 21.3 & & 19.2 & \\
\hline$<\mathrm{K}$ & $-7.74(-14.7,-0.75)$ & 0.0301 & $-2.70(-4.47,-0.94)$ & 0.0027 & $-8.72(-12.4,-5.06)$ & $<0.0001$ \\
\hline$\geq K$ & $5.10(4.44,5.77)$ & $<0.0001$ & $3.93(3.42,4.43)$ & $<0.0001$ & $4.26(3.87,4.65)$ & $<0.0001$ \\
\hline Difference of $\beta$-value between strata & $12.8(5.66,20.0)$ & 0.0005 & $6.63(4.65,8.61)$ & $<0.0001$ & $13.0(9.21,16.8)$ & $<0.0001$ \\
\hline Predicted value of sUA at break point & $308(304,312)$ & & $243(240,245)$ & & $267(264,270)$ & \\
\hline P-value for likelihood ratio test & $<0.001$ & & $<0.001$ & & $<0.001$ & \\
\hline
\end{tabular}

Model I: Adjusted for age

Model II: Adjusted for age, current smoking status, current drinking status, occupational types, SBP, DBP, fasting blood sugar (log 10 transformed), eGFR, LDL, triglyceride ( $\log _{10}$ transformed), and total cholesterol

Non-linear model: Adjusted for age, current drinking status, current smoking status, occupational types, SBP, DBP, fasting blood sugar (log 10 transformed), eGFR, LDL, triglyceride ( $\log _{10}$ transformed), and total cholesterol 

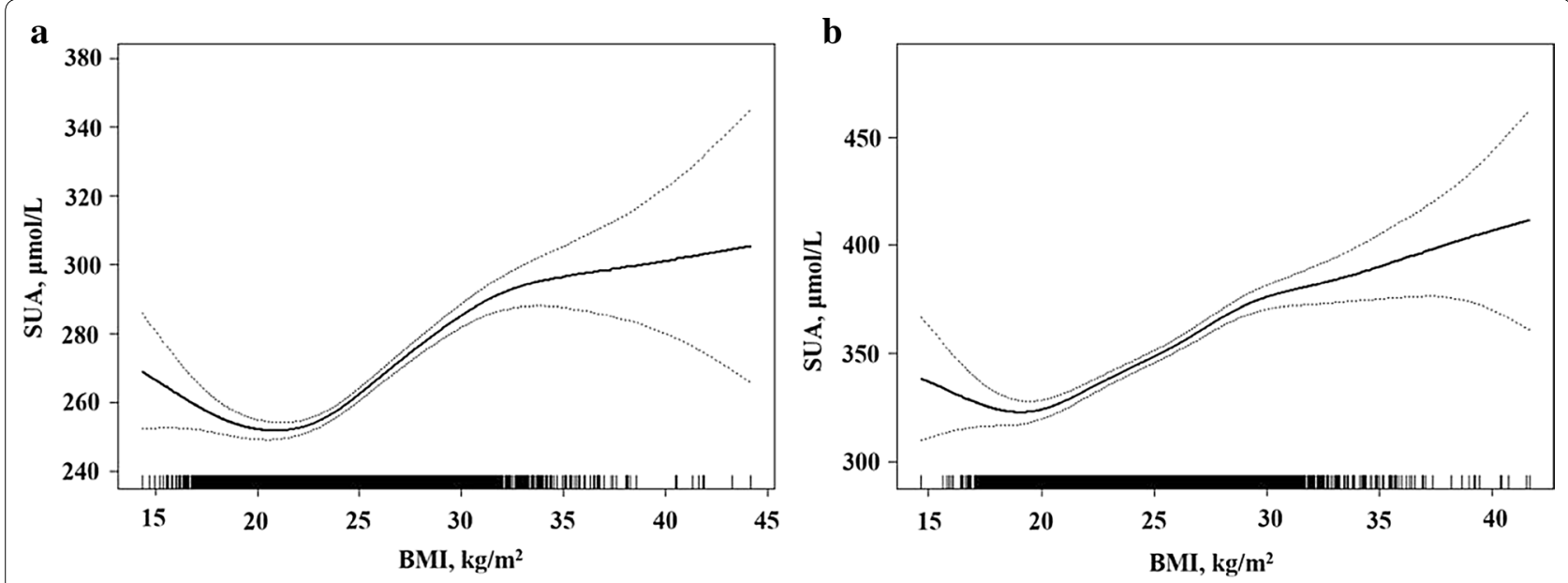

Fig. 1 Two-piece piecewise regression and smooth curve-fitting for association between SUA and BMI stratified by gender. a The two-piece wise smooth curve for BMI-SUA association in women. When the BMI was smaller or equal than $21.3 \mathrm{~kg} / \mathrm{m}^{2}$, there is a negative association between $\mathrm{BMI}$ and SUA. The regression coefficient $\beta$ was $-2.70(95 \% \mathrm{Cl}-4.47,-0.94)$. If BMl greater than $21.3 \mathrm{~kg} / \mathrm{m}^{2}$, a significant positive association was found with a regression coefficient of $3.93(95 \% \mathrm{Cl} 3.42,4.43)$. b The two-piece wise smooth curve for BMI-SUA association in women. When BMI smaller or equal to $19.1 \mathrm{~kg} / \mathrm{m}^{2}$, a negative BMI-SUA association was found with a regression coefficient of $-7.74(95 \% \mathrm{Cl}-14.7,-0.75)$. When BMI greater than $19.1 \mathrm{~kg} / \mathrm{m}^{2}$, a positive association was found, the coefficient was 5.10 ( $95 \% \mathrm{Cl}$ 4.44, 5.77). The two-piece wise models adjusted for age, current smoking status, current drinking status, occupational types, SBP, DBP, fasting blood sugar ( $\log _{10}$ transformed), eGFR, LDL, triglyceride (log 10 transformed), and total cholesterol

\section{Exploration of modifier and interaction effects on SUA-BMI-association}

We explored potential modifier or interaction effects from TG, TC, FBS, and LDL, and found that TG might be a potential interaction factor for SUA-BMI association (Table 4). After stratified analyses by tertiles of TG levels, we found the SUA-BMI association (regression coefficients per SD increase in BMI) among men was significantly increased from 3.74 (95\% CI of regression coefficient: $2.59,4.90)$ at tertile $1(<14.4 \mu \mathrm{mol} / \mathrm{L})$, to 4.89 $(95 \%$ CI 3.84, 5.95) at tertile $2(14.5-22.9 \mu \mathrm{mol} / \mathrm{L})$, and to $6.09(95 \%$ CI $5.13,7.05)$ at tertile $3(\geq 22.9 \mu \mathrm{mol} / \mathrm{L})$ with $P$ value of 0.002 for linear trend and $P$-value of 0.007 for interaction. Among women, a significant TG interaction was detected. The SUA-BMI regression coefficients were 2.12 (95\% CI 1.41, 2.83) for tertile 1, 3.29 (95\% CI 2.61, 3.97) for tertile 2, and 4.25 (95\% CI 3.51, 4.99) for tertile 3 with $P<0.0001$ for linear trend and $P=0.0002$ for interaction.

\section{Discussion}

Positive association between SUA and BMI was found among men and women. Using the two-piece piece-wise regression model, we found a U-shaped SUA-BMI relationship for both men and women. Although a positive association was maintained when the BMI was higher than $20 \mathrm{~kg} / \mathrm{m}^{2}$, a negative association was found when the BMI was lower than $20 \mathrm{~kg} / \mathrm{m}^{2}$. Our results suggested that SUA level might be a good index for BMI, depending on whether or not the participants were underweight.

Accumulating evidence suggests that elevated SUA levels are common comorbidities of obesity and are accompanied by gradually increasing BMI [17]. Dr. Rathmann and colleagues used the data from the Coronary Artery Risk Development in Young Adults (CARDIA) Study (1249 male and 1362 female black and white subjects aged 17-35 years with a 10-year follow-up) to evaluate changes in SUA with changes in components of the metabolic syndrome in young adults [18]. They found

Table 4 Potential interactions of triglyceride with sUA-BMI associations among men and women

\begin{tabular}{|c|c|c|c|c|c|}
\hline \multirow[t]{2}{*}{ Models } & \multicolumn{3}{|c|}{ Regression coefficients $(95 \% \mathrm{Cl})$ for triglyceride } & \multirow[t]{2}{*}{ P for interaction } & \multirow[t]{2}{*}{ P for linear trend } \\
\hline & $\mathrm{T} 1: 0.09-0.81, \mathrm{mmol} / \mathrm{L}$ & $\mathrm{T} 2: 0.81-1.21, \mathrm{mmol} / \mathrm{L}$ & T3:1.21-15.87, $\mathrm{mmol} / \mathrm{L}$ & & \\
\hline Men & $3.74(2.59,4.90)$ & $4.89(3.84,5.95)$ & $6.09(5.13,7.05)$ & 0.0074 & 0.0017 \\
\hline Women & $2.12(1.41,2.83)$ & $3.29(2.61,3.97)$ & $4.25(3.51,4.99)$ & 0.0002 & $<0.0001$ \\
\hline Total & $2.91(2.28,3.54)$ & $4.03(3.44,4.62)$ & $5.20(4.60,5.80)$ & $<0.0001$ & $<0.0001$ \\
\hline
\end{tabular}

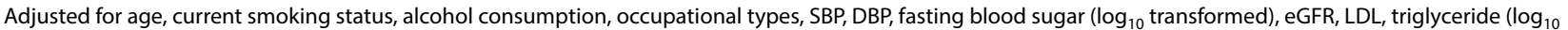
transformed) and total cholesterol 
that BMI had a significant independent linear association with UA in all race-sex-groups. Another Chinese study of 2962 patients with type 2 diabetes also observed a linear association between the prevalence of obesity and increasing SUA levels [19]. However, these studies only focused on the linear relationship between SUA and BMI, while our results indicated a strong U-shaped relationship for both men and women. Previous mechanism studies suggested that chronic inflammation contributed to the pathogenesis of obesity $[20,21]$; the infiltration and accumulation of macrophages in adipose tissue was demonstrated to be associated with increased tumor necrosis factor- $\alpha$ and interleukin 6 secretion [22, 23]. Similarly, macrophages also play an important role in the inflammation associated with gout/hyperuricemia [24-27]. Of note, physiological concentrations of SUA displayed anti-inflammatory effects both in vitro and in vivo [14] and thus might partly explain the U-shaped relationship between SUA and BMI.

Meanwhile, our results also showed a similar U-shaped SUA-BMI association and nadir point of BMI, around $20 \mathrm{~kg} / \mathrm{m}^{2}$, for men and women. The strength of the association was significantly stronger for men than women. A prospective study on 3857 Chinese participants with normal metabolic function [28] found that baseline SUA levels and metabolic syndrome during a mean follow-up of 5.41 years were more closely related in women than in men. A study among Mexican-origin infants, youth and adults [10] also found a stronger association between salivary UA levels and BMI for females than males. Although the mechanisms underlying these observations are still unclear, several studies indicated that differences in sex hormone levels may partially explain the effects. An analysis study on the data from 7662 women aged 20 years and older in the Third National Health and Nutrition Examination Survey (1988-1994) found that menopause was independently associated with higher SUA levels, and postmenopausal hormone use was associated with lower UA levels among postmenopausal women [29]. A study on 128 obese patients who underwent laparoscopic sleeve gastrectomy found that increased estradiol levels, decreased total testosterone levels, and increased estradiol/total testosterone ratios in obese female patients 6 months post-surgery might be related to SUA improvement [30]. Additionally, mechanism-related evidence also suggested that estradiol can affect fat metabolism and distribution in women.

In addition, we found an interaction effect of TG levels on the association between BMI and SUA; BMI had a stronger effect on SUA at higher TG levels. Similar interdependent relationships have been reported among SUA, C-reactive protein and interleukin 10 levels, which related to early hepatic damage [25]. As the hepatic manifestation of obesity and metabolic dysfunction, nonalcoholic fatty liver disease could result in hepatic damage. However, these assumptions need further investigation in additional well-designed studies.

Our study has several limitations. First, due to the inherent nature of cross-sectional designs, our results could not make a causality conclusion. Second, the participants were limited to coastal areas and had special diet features with more marine food products, such as sea-fish, shrimp, and shellfishes. Therefore the extension of these conclusions should be prudent. Furthermore, additional large-scale studies with representative populations are warranted to validate our conclusions.

\section{Conclusions}

Using the data from a general Chinese population, we found a U-shaped relationship between BMI and SUA for both men and women; and a stronger SUA-BMI association was found for men than for women. Further well-designed, large-scale longitudinal studies are needed to confirm our conclusions and evaluate the underlying mechanisms of the association.

\section{Abbreviations}

BMI: body mass index; BP: blood pressure; DBP: diastolic blood pressure; eGFR: estimated glomerular filtration rate; FBG: fasting blood glucose; H/LDL: high/ low-density lipoprotein cholesterol; LDL: low density lipoprotein; SBP: systolic blood pressure; SD: standard deviation; SUA: serum uric acid; TC: total cholesterol; TG: triglyceride; UA: uric acid.

\section{Acknowledgements}

Not applicable.

\section{Authors' contributions}

$\mathrm{HZ}$ conceived and designed the study. $\mathrm{HZ}$ and $\mathrm{YeC}$ wrote this paper. ZL, ZC, YiC and LM performed the experiments. $\mathrm{HZ}, \mathrm{YW}$ and $\mathrm{CL}$ analyzed the data. All authors read and approved the final manuscript.

\section{Funding}

The study was supported by the Natural Science Foundation of China (Grant Number 81600601).

\section{Availability of data and materials}

All data generated or analyzed during this study are included in this published article.

\section{Ethics approval and consent to participate}

The study protocol was approved by the ethics committee of the Affiliated Hospital of Qingdao University.

\section{Consent for publication}

Individual informed consent was obtained from each participant.

\section{Competing interests}

The authors declare that they have no competing interests.

\section{Author details}

${ }^{1}$ Department of Endocrinology and Metabolism, The Affiliated Hospital of Qingdao University, 16 Jiangsu Road, Qingdao, Shandong 266003, China. ${ }^{2}$ Heze Medical College, Heze, Shandong, China. ${ }^{3}$ Shandong Provincial Key Laboratory of Metabolic Diseases, The Affiliated Hospital of Qingdao University, Qingdao, China. 
Received: 25 July 2019 Accepted: 15 November 2019

Published online: 25 November 2019

\section{References}

1. Maiuolo J, Oppedisano F, Gratteri S, Muscoli C, Mollace V. Regulation of uric acid metabolism and excretion. Int J Cardiol. 2016;213:8-14.

2. Kanbay M, Jensen T, Solak Y, Le M, Roncal-Jimenez C, Rivard C, Lanaspa MA, Nakagawa T, Johnson RJ. Uric acid in metabolic syndrome: from an innocent bystander to a central player. Eur J Intern Med. 2016;29:3-8.

3. Zhou H, Wang Y, Cui L, Chen Y, Li C, Zhao J. The ongoing role of serum uric acid in blood pressure. Clin Exp Hypertens. 2017:39:601-5.

4. Rizzo M, Obradovic M, Labudovic-Borovic M, Nikolic D, Montalto G, Rizvi AA, Mikhailidis DP, Isenovic ER. Uric acid metabolism in pre-hypertension and the metabolic syndrome. Curr Vasc Pharmacol. 2014;12:572-85.

5. Xu YL, Xu KF, Bai JL, Liu Y, Yu RB, Liu CL, Shen C, Wu XH. Elevation of serum uric acid and incidence of type 2 diabetes: a systematic review and metaanalysis. Chronic Dis Transl Med. 2016;2:81-91.

6. Lima WG, Martins-Santos ME, Chaves VE. Uric acid as a modulator of glucose and lipid metabolism. Biochimie. 2015;116:17-23.

7. Zheng R, Chen C, Yang T, Chen Q, Lu R, Mao Y. Serum uric acid levels and the risk of obesity: a longitudinal population-based epidemiological study. Clin Lab. 2017:63:1581-7.

8. Tremmel M, Gerdtham UG, Nilsson PM, Saha S. Economic burden of obesity: a systematic literature review. Int J Environ Res Public Health. 2017;14:435.

9. Upadhyay J, Farr O, Perakakis N, Ghaly W, Mantzoros C. Obesity as a disease. Med Clin North Am. 2018;102:13-33.

10. Martinez AD, Ruelas L, Granger DA. Association between body mass index and salivary uric acid among Mexican-origin infants, youth and adults: gender and developmental differences. Dev Psychobiol. 2017:59:225-34

11. Tanaka K, Ogata S, Tanaka H, Omura K, Honda C, Hayakawa K. The relationship between body mass index and uric acid: a study on Japanese adult twins. Environ Health Prev Med. 2015;20:347-53.

12. Wang $H$, Wang $L$, Xie R, Dai W, Gao C, Shen P, Huang X, Zhang F, Yang X, Ji $G$. Association of serum uric acid with body mass index: a cross-sectional study from Jiangsu Province, China. Iran J Public Health. 2014;43:1503-9.

13. Yue JR, Huang CQ, Dong BR. Association of serum uric acid with body mass index among long-lived Chinese. Exp Gerontol. 2012;47:595-600.

14. Lai JH, Luo SF, Hung LF, Huang CY, Lien SB, Lin LC, Liu FC, Yen BL, Ho LJ. Physiological concentrations of soluble uric acid are chondroprotective and anti-inflammatory. Sci Rep. 2017;7:2359.

15. Spiga R, Marini MA, Mancuso E, Di Fatta C, Fuoco A, Perticone F, Andreozzi F, Mannino GC, Sesti G. Uric acid is associated with inflammatory biomarkers and induces inflammation via activating the NF-kappaB signaling pathway in HepG2 cells. Arterioscler Thromb Vasc Biol. 2017;37:1241-9.

16. Thottam GE, Krasnokutsky S, Pillinger MH. Gout and metabolic syndrome: a tangled web. Curr Rheumatol Rep. 2017;19:60.

17. Kuwabara M, Kuwabara R, Hisatome I, Niwa K, Roncal-Jimenez CA, Bjornstad P, Andres-Hernando A, Sato Y, Jensen T, Garcia G, et al. "Metabolically healthy" obesity and hyperuricemia increase Risk for hypertension and diabetes: 5-year Japanese cohort study. Obesity. 2017;25:1997-2008.

18. Chen MY, Zhao CC, Li TT, Zhu Y, Yu TP, Bao YQ, Li LX, Jia WP. Serum uric acid levels are associated with obesity but not cardio-cerebrovascular events in Chinese inpatients with type 2 diabetes. Sci Rep. 2017;7:40009.

19. Oberbach A, Neuhaus J, Inge T, Kirsch K, Schlichting N, Bluher S, Kullnick Y, Kugler J, Baumann S, Till H. Bariatric surgery in severely obese adolescents improves major comorbidities including hyperuricemia. Metabolism. 2014:63:242-9.

20. Tanaka M, Itoh M, Ogawa Y, Suganami T. Molecular mechanism of obesity-induced 'metabolic'tissue remodeling. J Diabetes Investig. 2018;9:256-61.

21. Koca TT. Does obesity cause chronic inflammation? The association between complete blood parameters with body mass index and fasting glucose. Pak J Med Sci. 2017;33:65-9.

22. Subramanian V, Ferrante AW Jr. Obesity, inflammation, and macrophages. Nestle Nutr Workshop Ser Pediatr Program. 2009;63:151-9 (discussion 9-62, 259-68).

23. Unek IT, Bayraktar F, Solmaz D, Ellidokuz H, Sisman AR, Yuksel F, Yesil S. The levels of soluble CD40 ligand and C-reactive protein in normal weight, overweight and obese people. Clin Med Res. 2010;8:89-95.

24. Lu J, Hou X, Yuan X, Cui L, Liu Z, Li X, Ma L, Cheng X, Xin Y, Wang C, et al. Knockout of the urate oxidase gene provides a stable mouse model of hyperuricemia associated with metabolic disorders. Kidney Int 2018:93:69-80

25. Leon-Pedroza Jl, Escobedo G, Gonzalez-Chavez A. Relationship of hyperuricemia with low density lipoprotein, liver function tests and markers of systemic inflammation in patients with morbid obesity. Gac Med Mex. 2017;153:S42-50.

26. Ayna G, Krysko DV, Kaczmarek A, Petrovski G, Vandenabeele P, Fesus L. ATP release from dying autophagic cells and their phagocytosis are crucial for inflammasome activation in macrophages. PLOS ONE. 2012;7:e40069.

27. Gicquel T, Robert S, Loyer P, Victoni T, Bodin A, Ribault C, Gleonnec F, Couillin I, Boichot E, Lagente V. IL-1 beta production is dependent on the activation of purinergic receptors and NLRP3 pathway in human macrophages. FASEB J. 2015;29:4162-73.

28. Yang T, Chu CH, Bai CH, You SL, Chou YC, Chou WY, Chien KL, Hwang LC, Su TC, Tseng CH, et al. Uric acid level as a risk marker for metabolic syndrome: a Chinese cohort study. Atherosclerosis. 2012;220:525-31.

29. Hak AE, Choi HK. Menopause, postmenopausal hormone use and serum uric acid levels in US women-the Third National Health and Nutrition Examination Survey. Arthritis Res Ther. 2008;10:R116.

30. Zhang X, Zhu C, Gao J, Mei F, Yin J, Bu L, Cheng X, Sheng C, Qu S. Gender difference in the relationship between serum uric acid reduction and improvement in body fat distribution after laparoscopic sleeve gastrectomy in Chinese obese patients: a 6-month follow-up. Lipids Health Dis. 2018;17:288.

\section{Publisher's Note}

Springer Nature remains neutral with regard to jurisdictional claims in published maps and institutional affiliations.
Ready to submit your research? Choose BMC and benefit from:

- fast, convenient online submission

- thorough peer review by experienced researchers in your field

- rapid publication on acceptance

- support for research data, including large and complex data types

- gold Open Access which fosters wider collaboration and increased citations

- maximum visibility for your research: over $100 \mathrm{M}$ website views per year

At BMC, research is always in progress.

Learn more biomedcentral.com/submissions 